\title{
Di and tripeptides from marine sources can target adipogenic process and contribute to decrease adipocyte number and functions
}

\author{
Ben Henda Yesmine ${ }^{1}$, Laamari Mariem ${ }^{1}$, Lanneluc Isabelle ${ }^{1}$, Travers Marie-Agnès ${ }^{2}$, \\ Agogué Hélène ${ }^{3}$, Arnaudin Ingrid ${ }^{1}$, Bridiau Nicolas ${ }^{1}$, Maugard Thierry ${ }^{1}$, Piot Jean-Marie ${ }^{1}$, \\ Sannier Frédéric ${ }^{1}$, Bordenave-Juchereau Stéphanie ${ }^{1,}$
}

${ }^{1}$ Université de La Rochelle, Laboratoiree LIENSs UMR CNRS-7266, UFR Sciences Technologies Santé, F-17042 La Rochelle, France

2 IFREMER, RBE-SG2M-LGPMM, Avenue de Mus de Loup, F-17390 La Tremblade, France

${ }^{3}$ Molecular Core Facility, Laboratoire LIENSs UMR7266, CNRS-Université de La Rochelle, 2 rue Olympe de Gouges, F-17000 La Rochelle, France

* Corresponding author : Stéphanie Bordenave-Juchereau, Tel.: +33 546458562; fax: +33 546458265 ; emai address : sbordena@univ-Ir.fr

\begin{abstract}
:
The effect of 11 marine-derived cryptides was investigated on proliferation, differentiation and maturation of human white pre-adipocytes (HWP). They were all formerly identified as potent Angiotensin-Converting-Enzyme inhibitors.Val-Trp (VW), Val-Tyr (VY), Lys-Tyr (KY), Lys-Trp (KW), IleTyr (IY), Ala-Pro (AP), Val-Ile-Tyr (VIY), Leu-Lys-Pro (LKP), Gly-Pro-Leu (GPL), Ala-Lys-Lys (AKK) and Val-Ala-Pro (VAP) were previously found in fish products and coproducts as well as other marine resources like wakame. Treatment with AP, VAP and AKK greatly affected viability of HWP during the proliferation period while $\mathrm{KW}$ and $\mathrm{VW}$ treatment reduced the number of viable cells during the differentiation stage. A GPL and IY incubation during the differentiation stage allowed the decrease of their final lipid content, of the GPDH activity and of the mRNA level of adipocyte markers (aP2, GLUT4, LPL and AGT). Moreover, a down regulation of both PPARy and C/EBPa expression, two key regulators of adipogenesis, was observed.These findings indicate that small bioactive peptides from marine protein hydrolysates can target adipogenesis and thus could regulate energy metabolism disorders.
\end{abstract}

\section{Highlights}

- The effect of marine derived cryptides on adipogenesis of human adipocytes was investigated. Marine cryptides ACE-inhibitory activity is not related with adipogenesis. AP, VAP and AKK may inhibit growth of preadipocytes during proliferation stage. $~ G P L$ and IY down-regulated adipocyte specific differentiation markers.

Keywords : Bioactive peptides, Obesity, Human white pre-adipocytes, Proliferation, Differentiation, Adipocyte differentiation markers 


\section{Introduction}

Around 1.6 billion adults (over the age of 15 years) are considered to be over weighted (with a body mass index (BMI) between 25 and $30 \mathrm{~kg} / \mathrm{m}^{2}$ ) and 400 million are considered obese (with a BMI $\geq 30 \mathrm{~kg} / \mathrm{m}^{2}$ ) (Stothard, Tennant, Bell, \& Rankin, 2009). These data demonstrate the urgency to establish effective strategies for prevention and treatment of obesity. Among ways to reduce obesity, the decrease of energy/food intake and the increase of energy expenditure (Park, Jeon, Kim, \& Han, 2013) are of importance but targeting adipocyte physiology and cell cycle could also be a solution. Indeed, recent studies have examined how far inhibition of preadipocyte proliferation, differentiation, lipogenesis or promotion of lipolysis and fat oxidation (Wang, \& Jones, 2004) can reduce obesity. Obesity is characterized at the cellular level by an increase in the number and size of adipocytes originating from fibroblastic pre-adipocytes in adipose tissues (Furuyashiki et al., 2004). Pre-adipocytes, which can then be differentiated into mature adipocytes and modulate body fat mass, play a key role in obesity (Park et al., 2013).

At a molecular level, differentiation is a well-organized program characterized by the loss of pre-adipocyte markers and sequential changes in the expression of general and adipocytespecific genes that determine the specific adipocyte phenotype (Catalioto, Maggi, \& Giuliani, 2009). These changes in gene expression during differentiation program are induced by a coordinated expression and action of transcription factors. Consequently, early, intermediate and late mRNA and protein markers can be detected and finally triglycerides (TG) accumulation can be observed.

Moreover, mature adipocytes express all components of the renin-angiotensin system (RAS), including angiotensinogen (AGT), the sole precursor of Angiotensin II (Ang II), type 1 (AT1) and type 2 (AT2) angiotensin receptors as well as the angiotensin peptide forming enzymes: renin, angiotensin-I-converting enzyme (ACE), and chymase (Engeli, Negrel \& Sharma, 
2000). This local RAS exerts important auto/paracrine functions in modulating lipogenesis, lipolysis and adipogenesis (Massiera et al., 2001). Ang II, a potent vasoconstrictor and key player in hypertension, increases lipogenesis and TG accumulation in 3T3-L1 pre-adipocytes and human adipocytes (Jones, Standridge, \& Moustaid, 1997). In addition, Crandall et al. (1999) observed that the stimulation of human pre-adipocytes with Ang II resulted in an acceleration of the G1-phase of the cell cycle and an increased expression of the cell cycle regulator cyclin D1. This suggests that Ang II can contribute to the growth and the development of adipose tissues. Thus blockade of the RAS and its main enzyme, ACE, may be of particular benefit in the management of obesity probably by reducing adipose size and decreasing functional adipocytes number. ACE- inhibitors (ACEI) may thus contribute to attenuate obesity by acting on adipocyte life cycle.

Since synthetic ACE inhibitors have often side effects, dietary bioactive peptides able to inhibit ACE could be interesting alternatives in the management of obesity.

We previously demonstrated that incubation of human adipocytes with a goat whey hydrolysate containing ACEI peptides decreased the proliferation of pre-adipocyte and reduced the lipid content of mature adipocytes (Hammé, Sannier, Piot, \& BordenaveJuchereau, 2010). The aim of this current work is to assess whether cryptides, bioactive peptides hidden within the sequence of a parent protein, already identified as potent ACEI can act on adipogenesis. These cryptides were selected in marine products such as fish, seaweed, and shellfish for their previously documented high inhibitory ACE potency, as demonstrated in administration studies with spontaneously hypertensive rats (SHR) (Ono, Hosokawa, Miyashita, \& Takahashi, 2003). They also were chosen for their short-chain nature giving them the opportunity to penetrate in tissue or cells and to resist to endogenous proteases. They can be found in sea bream, sardine or chicken indicating that theses sequences are ubiquitous. 
93 We investigated the ability of 6 dipeptides (Val-Trp (VW), Val-Tyr (VY), Lys-Tyr (KY), 94 Lys-Trp (KW), Ile-Tyr (IY), Ala-Pro (AP)) and 5 tripeptides (Val-Ile-Tyr (VIY), Leu-Lys-Pro 95 (LKP), Gly-Pro-Leu (GPL), Ala-Lys-Lys (AKK), Val-Ala-Pro (VAP)) to act on adipocyte 96 development. A quite high concentration of $100 \mu \mathrm{M}$ was chosen for all cryptides tested since it 97 exhibited a noticeable effect on adipocytes development. Viability was measured after 98 proliferation and differentiation of adipocytes. The regulatory effect of these peptides on the 99 differentiation stage was analyzed by measuring the mRNA expression changes of adipocyte 100 differentiation markers as well as assessing GPDH activity. Effect of peptides on lipid 101 accumulation was also monitored after various periods of exposition. 


\section{Material and methods}

103

104

105

106

107

108

109

110

111

112

113

114

\subsection{Material}

Human white pre-adipocyte (HWP) were purchased as cryopreserved pre-adipocytes from PromoCell (Heidelberg, Germany) and originated from subcutaneous white adipose tissue obtained from a female/62 years/Caucasian. The growth and differentiation media for preadipocytes, the nutrition medium for adipocytes and supplements for each medium were purchased from PromoCell.

The antibiotic solution containing Penicillin 10,000 U / ml and Streptomycin, $10 \mathrm{mg} / \mathrm{ml}$ was from PAN Biotech. GmbH (Aidenbach, Germany).

MTT (3-(4.5-dimethylthiazolyl)-2.5-diphenyl-tetrazoliumbromide), DMSO, Caffeine, Oil red O stain and Bradford reagent were from Sigma-Aldrich (Saint-Quentin Fallavier, France).

Synthetic peptides were purchased at $>90 \%$ of purity from GeneCust (Dudelange, Luxembourg). Purity of each peptide was checked after solubilisation in adequate buffer and their molecular mass and aminoacid sequence were confirmed by HPLC ESI-MS.

\subsection{Cell Culture}

HWP cells were cultured according to the manufacturer's instructions with slight modifications. Briefly, cells not exceeding 4 passages were cultured at $37{ }^{\circ} \mathrm{C}$ in a humidified $5 \% \mathrm{CO}_{2}$ atmosphere and grown in a preadipocyte growth medium (GM) with $1 \%$ antibiotics (proliferation stage).

For adipocyte differentiation, confluent cultures (Day 0) were stimulated to differentiation with pre-adipocyte differentiation medium (DM) containing d-Biotin $8 \mu \mathrm{g} / \mathrm{ml}$, insulin 0.5 $\mu \mathrm{g} / \mathrm{ml}$, dexamethasone $400 \mathrm{ng} / \mathrm{ml}$, isobutylmethylxanthine $44 \mu \mathrm{g} / \mathrm{ml}$, L-thyroxine $9 \mathrm{ng} / \mathrm{ml}$ and 
ciglitazone $3 \mu \mathrm{g} / \mathrm{ml}$. After 4 days, medium was changed to the adipocyte nutrition medium (NM) containing Fetal Calf Serum 3\%, d-Biotin $8 \mu \mathrm{g} / \mathrm{ml}$, insulin $0.5 \mu \mathrm{g} / \mathrm{ml}$ and dexamethasone $400 \mathrm{ng} / \mathrm{ml}$, Cells were cultured in nutrition medium for further 4,8 or 12 days according the test. By day 16, cells contained large lipid droplets and were considered as mature adipocytes.

Cryptides, dissolved in dimethyl sulphoxide (DMSO stock solution, $10^{-2} \mathrm{M}$ ), were added at a final concentration of $100 \mu \mathrm{M}$ to $\mathrm{GM}$ or $\mathrm{DM}$ and/or $\mathrm{NM}$ in order to observe their effects. Each medium was replaced every 2 days by fresh medium containing cryptides.

\subsection{MTT assay}

To detect the effect of marine cryptides on the viability of HWP during proliferation stage, HWP were seeded in 96-well culture plates at a density of 5000 cells/well and cultured in GM with or without $100 \mu \mathrm{M}$ of marine cryptides. After $24 \mathrm{~h}$ or $72 \mathrm{~h}$ of treatment, $25 \mu \mathrm{l}$ MTT $(5 \mathrm{mg} / \mathrm{mL})$ were added to each well. The plates were incubated at $37^{\circ} \mathrm{C}$ for $4 \mathrm{~h}$, followed by the addition of DMSO (200 $\mu \mathrm{l} /$ well), and incubated at $37^{\circ} \mathrm{C}$ for $10 \mathrm{~min}$. Optical density (OD) was measured at $570 \mathrm{~nm}$ using UV spectrometer Devices versa Max microplate reader (Molecular devices, Sunnyvale, CA, USA). Non treated-cells were used as control.

To detect the effect of some cryptides on the viability of HWP cells during differentiation stage, cells were cultured with $100 \mu \mathrm{M}$ of marine cryptides from day 0 to day 12 . MTT assay was carried out on days 3, 6, 9 and 12 using the method described above.

\subsection{Oil-Red-O staining and quantification of lipid accumulation}

Lipid accumulation was estimated in mature adipocytes, cultured in 24-well plates at a density of $10^{4} \mathrm{cells} / \mathrm{ml}$. On day 16 , medium was removed and cells were washed twice with PBS, fixed 1h with $500 \mu \mathrm{l} 4 \%$ formaldehyde in PBS at room temperature, rinsed with $500 \mu 160 \%$ 
2-propanol and dried for $5 \mathrm{~min}$. Cells were stained with $200 \mu \mathrm{l}$ Oil-Red-O solution (Oil-Red-O stock solution $(5 \mathrm{mg} / \mathrm{ml}$ in pure isopropanol)/ water, 3/2, v/v)) at room temperature for $10 \mathrm{~min}$. Then the Oil-Red-O solution was removed and cells were washed 4 times with distilled water to remove excess of stain. Images were obtained using Eclipse TS100 inverted microscope (100X) equipped for phase-contrast microscopy (Nikon, Yokohama, Japan).

For quantification, the stained oil droplets were dissolved in $750 \mu 1$ isopropanol for $10 \mathrm{~min}$ and the lipid content evaluated by measuring the optical absorbance at $540 \mathrm{~nm}$ using Fluostar Omega spectrofluorometer (BMG LABTECH GmbH, Ortenberg, Germany).

\subsection{Quantification of the GPDH activity}

HWP were seeded in 24-well plates, grown to confluence and treated during the differentiation period (from day 0 to day 8 ) with $100 \mu \mathrm{M}$ of cryptides (treated cells). A control with medium only was included in the study. On day 8, cells were washed twice with PBS, then enzyme extraction buffer was added to induce cell lysis, and cells extracts were collected by scraping. After centrifugation at $7,840 \mathrm{~g}$ for $5 \mathrm{~min}$ at $4^{\circ} \mathrm{C}$, the glycerol-3-phosphate dehydrogenase (GPDH) specific activity of supernatant was measured with the GPDH Activity Assay Kit (TaKaRa Bio Inc., Shiga, Japan). GPDH Protein concentration was measured using the Bradford protein assay (Bradford, 1976). Values for GPDH activity were expressed as a proportion of control (100\%).

\subsection{Real time PCR}

HWP were seeded at $10^{5}$ cell $/ \mathrm{ml}$ in six well plates, grown to confluence, and then treated with $100 \mu \mathrm{M}$ of cryptides during differentiation period (from day 0 to day 8). A control with medium only was included in the study. On day 8, cells were collected. Total RNA was extracted using the NucleoSpin RNA II kit (Macherey-Nagel, Düren, Germany) according to the manufacturer's instructions. The RNA samples were treated using the Ambion DNA-free 
171 kit (Life Technologies, Carlsbad, USA). RNA was quantified at $260 \mathrm{~nm}$ using NanoDrop

1722000 UV-Vis Spectrophotometer (Thermo Scientific, USA), and sample integrity was 173 checked on $1 \%$ agarose gel electrophoresis.

Reverse-transcription of RNA (500 ng) was carried out using the Cloned AMV First-Strand cDNA Synthesis Kit (Invitrogen, Carlsbad, CA, USA), with random primers following the manufacturer's instructions.

A real time PCR was then performed on cDNA samples to evaluate the mRNA expression of human genes PPAR $\gamma, \mathrm{C} / \mathrm{EBP} \alpha, \mathrm{aP} 2, \mathrm{GLUT} 4, \mathrm{LPL}$ and AGT. Human $\beta$-actin was used as an endogenous reference.

Reactions were run on an Mx3000P Real-Time Thermocycler (Stratagene, La Jolla, CA,USA) using Brilliant III Ultra-Fast SYBR Green kit (Applied Biosystems, Foster City, CA, USA) with the following cycling parameters: 1 cycle at $95^{\circ} \mathrm{C}$ for 3 min followed by 40 cycles at $95^{\circ} \mathrm{C}$ for $10 \mathrm{~s}$ and $60^{\circ} \mathrm{C}$ for $20 \mathrm{~s}$. Each reaction was performed in duplicate in a final volume of $20 \mu \mathrm{l}$ containing $5 \mu \mathrm{L}$ cDNA (1/20 dilution), $2 \times$ Brilliant III Ultra-Fast SYBR Green Master Mix $(10 \mu \mathrm{L})$, and with an optimal concentration of gene specific forward and reverse primers (400 nM). The primer (Eurofins MWG Operon, Ebersberg, Germany) sequences are presented in table 1 .

Relative quantification values were expressed using the $2^{-\Delta \Delta \mathrm{Ct}}$ method: the amount of target message (PPAR $\gamma, \mathrm{C} / \mathrm{EBP} \alpha$, aP2, GLUT4, LPL, or AGT in mRNA treated adipocytes) was normalized to the internal reference ( $\beta$-actin) and compared to the calibrator (PPAR $\gamma$, C/EBP $\alpha$, aP2, GLUT4, LPL, or AGT in untreated adipocytes).

The primers were validated by testing PCR efficiency using standard curves $(95 \% \leq$ efficiency $\leq 105 \%$ ). PCR product specificity was evaluated by generating a dissociation curve following 
194 the manufacturer's recommendations. All results were obtained from at least three 195 independent experiments.

196

197

\subsection{Statistical Analysis.}

Data are presented as means \pm standard error. Statistical analyses were conducted using software Origin 6.0. A significant difference from the control group was analyzed with an unpaired Student $t$ test. $P$ values $<0.05$ data were considered significantly different from those of the control.

\section{Results}

\subsection{Effect of marine cryptides on the viability of HWP cells during proliferation and} differentiation

To detect the effect of marine cryptides on viability of HWP during the proliferation stage, cells were treated with $100 \mu \mathrm{M}$ of VW, KW, IY, KY, VIY, VY, LKP, GPL, AKK, AP, and VAP. MTT analysis was carried out after $24 \mathrm{~h}$ (Figure 1A) and $72 \mathrm{~h}$ (Figure 1B) of treatment. As shown in Figure1A; AP, VAP and AKK affected cell viability significantly $(p<0.01)$. VAP exhibited the greatest cell viability inhibition with a decrease of viability of $59.3 \pm 7.3 \%$ and $81.1 \pm 4.3 \%$ after 1 and 3 days of treatment respectively when compared to controls. AP and AKK decreased viability by $46.4 \pm 3.9$ and $24.5 \pm 5.3 \%$ and by $55.8 \pm 4.5$ and $22.8 \pm 4.3 \%$, respectively, after 1 and 3 days of incubation while other cryptides tested showed no significant effect $(p>0.05)$ on the HWP viability after 1 and 3 days of treatment during the proliferation stage. After $24 \mathrm{~h}$, differences among effective peptides was significant between AKK and AP, VAP and AP, but not between AKK and AP. After $72 \mathrm{~h}$, all values obtained after treatment with AKK, AP and VAP were significantly different. 
Peptides exhibiting no anti-proliferative action during growth stage were then added in HWP medium during the differentiation period. $100 \mu \mathrm{M}$ of VW, VY, IY, KY, VIY, KW, GPL and LKP were added on cells and MTT analysis was carried out after 3, 6, 9 and 12 days during the differentiation stage. The cell viability was not affected after $72 \mathrm{~h}$ except in the presence of VW and KW which were found to reduce significantly $(p<0.05)$ the number of viable cells when compared with control (Figure 1C). For example, after 12 days, VW and KW decreased cell viability by $32.8 \pm 5.1(p<0.05)$ and $26.8 \pm 4.3 \%(p<0.05)$, respectively.

\subsection{Effect of marine cryptides on residual lipid content of mature adipocytes}

The inhibitory effect of cryptides on the final lipid content of mature adipocytes was studied, using those which did not exhibit adverse effect on adipocyte viability (GPL, IY, VIY, KY, VY and LKP). $100 \mu \mathrm{M}$ of cryptides or $100 \mu \mathrm{M}$ caffeine (chosen as a lipolytic reference molecule) was added to the culture medium. Figure 2A, B, C, D show the staining observed and Fig. 3, the quantitative results of mature adipocytes at day 16. As expected, the staining of HWP cultured in DM and NM without treatment revealed plenty of lipid droplets, indicating an almost total differentiation (Figure 2A).

Cells grown in DM and NM in presence of GPL (Figure 2B), IY (Figure 2C) or caffeine (Figure 2D), showed less oil droplets than the control cells indicating an inhibition of lipid filling when cells were treated with these cryptides. GPL treatment showed the maximum reduction on lipid content compared with control group (Figure 2A). This was confirmed by the quantitative Oil-Red-O staining measurements (Figure 3), which indicated that HWP grown in the presence of GPL exhibited a reduction of the lipid content by $20.9 \pm 4.0 \%$ $(p<0.05)$. In addition, IY and VIY reduced significantly $(p<0.05)$ the final lipid accumulation by $10.4 \pm 4.1$ and $9.3 \pm 2.5 \%$, respectively. 
Analysis of the results obtained with KY, VY and LKP (Figure 3) showed no significant difference $(p>0.05)$ when compared with control cells.

As we observed a reduction of the final lipid content after adipocytes incubation with GPL, IY, and VIY during the differentiation stage, we then examined if these peptides could potentially act on human adipose conversion at early or late stages of the differentiation programs.

For that purpose, $100 \mu \mathrm{M}$ of IY, GPL, and VIY were added to the differentiation medium or to the nutrition medium. The extent of differentiation process leading to the filling of adipocytes with lipid droplets was monitored by quantitative Oil-Red-O staining at day 16 (Figure 4). When peptides were incubated with cells during the early stage of differentiation, GPL and IY reduced significantly $(p<0.05)$ the final lipid accumulation by $13.5 \pm 3.6 \%$ and $8.3 \pm 0.3 \%$, respectively, while VIY had only a minor effect on the final lipid content (no significant $p>0.05)$. However, none of the peptides tested affected significantly $(p>0.05)$ the final lipid content when incubated during the second period of differentiation process.

\subsection{Effect of marine cryptides on GPDH activity}

The activity of GPDH, involved in TG synthesis, was measured on day 8 after the addition of $100 \mu \mathrm{M}$ of GPL, IY, VIY, KY, VY and LKP during differentiation. We measured a really low GPDH activity in undifferentiated pre-adipocytes (data not shown). As shown in Figure 5, GPDH activity decreased by $33.7 \pm 10.6 \%(p<0.05)$ in HWP cells incubated with GPL compared with untreated cells. Cells treated with IY also had a GPDH activity significantly $(p<0.05)$ decreased by $25.8 \pm 4.8 \%$. On the other hand, there was no significant $(p>0.05)$ change in the GPDH activity of HWP cells treated with other tested peptides (VY, VIY, KY or LKP). 


\subsection{Effect of marine cryptides on the expression of adipogenic marker genes}

265

266

267

In order to assess appropriate genetic changes during the HWP cells differentiation, RT-PCR assay was first carried out for undifferentiated cells and cells after 8 days of differentiation, without peptide treatment. We checked that mRNA expression level of all genes tested increased as differentiation proceeded, supporting that the differentiation of pre-adipocyte was induced properly (data not shown).

We previously showed that GPL and IY decreased significantly the total lipid content and the GPDH activity indicating an action during early differentiation process. The effect of incubating HWP with GPL or IY was measured on the expression of markers of adipocyte differentiation (LPL, GLUT4, aP2 and AGT). In this study, we added the cryptide LKP as a negative control since no change on lipid content or GPDH activity was observed previously with this cryptide.

HWP were treated at day 8 with $100 \mu \mathrm{M}$ of the above mentioned peptides. The effect of GPL, IY and LKP on mRNA expression of adipogenic genes during HWP differentiation is presented Figure 6. The mRNA expression of GLUT4 and aP2 were significantly downregulated by approximately two-fold $(p<0.01)$ after GPL treatment. When compared with untreated cells, the addition of GPL to the medium resulted also in a decrease of relative LPL and AGT mRNA expression to $0.81 \pm 0.09(p<0.05)$ and $0.70 \pm 0.05(p<0.01)$, respectively.

The mRNA expression level of LPL, GLUT4, aP2, and AGT were also down-regulated by IY treatment (Figure 6A, B, C, D) but in a lesser extent. However, LKP did not affect gene expression except for aP2 whose expression increased.

We then investigated whether, after 8 days of treatment during differentiation, GPL and IY could suppress adipogenesis through the PPAR $\gamma$ and C/EBP $\alpha$ pathways. GPL and IY 
significantly down regulated mRNA expression of PPAR $\gamma(p<0.05)$ (Figure 6E) and C/EBP $\alpha$ $(p<0.01)$ (Figure 6F). However, the effect of IY were weaker than the one of GPL: the relative mRNA expression of PPAR $\gamma$ and $\mathrm{C} / \mathrm{EBP} \alpha$ were decreased to $0.70 \pm 0.09$ and $0.47 \pm 0.01$, respectively, compared to the control cells after GPL treatment (Figure 6E, F), while relative mRNA expression of PPAR $\gamma$ and $\mathrm{C} / \mathrm{EBP} \alpha$ were decreased to $0.80 \pm 0.09$ and to $0.78 \pm 0.06$ when cells were incubated with IY.

\section{Discussion}

Various dietary bioactive compounds like phytochemicals, have already shown interesting effects on adipose cells (Rayalam, Della-Fera, \& Baile, 2008). Marine protein hydrolysates were also able to reduce visceral adipose tissue mass through the modulation of plasma bile acids level (Liaset, et al., 2009) and control satiety (Bougatef, et al., 2010). We focus our attention on peptides isolated from marine hydrolysate and investigated theirs in vitro impacts on the proliferation and the differentiation of human white pre-adipocytes cells in order to identify theirs effects on the adipogenic process.

All the cryptides chosen in our investigation were reported to have an antihypertensive potential by the inhibition of ACE activity (Ben Henda et al. 2013). The link between inhibitors of ACE and weight is currently under investigation and targeting the adipocyte cell cycle seems to be one of the solutions proposed against obesity.

We first defined the cryptide concentration of study and decided to work with a quite high concentration $(100 \mu \mathrm{M})$ in order to discriminate quickly the most interesting peptides: those exerting an action on the development of adipocytes.

We demonstrated that all ACE inhibitory peptides could not affect the viability of HWP cells during proliferation and differentiation. Among 11 cryptides tested, 5 were found to be toxic 
for human adipocytes at a concentration of $100 \mu \mathrm{M}$ : AKK, AP and VAP decreased preadipocytes viability while KW and VW exert their toxic effect during the differentiation stage. The decrease of cell numbers was probably due to the inhibition of cell division and/or induction of cell death by apoptosis in HWP. This was already demonstrated by a number of natural products such as polyphenol compounds which were shown to inhibit preadipocytes proliferation and induce apoptosis. For example, quercetin and diphlorethohydroxycarmalol (DPHC) induced apoptosis in 3T3-L1 pre-adipocyte by decreasing mitochondria membrane potential, down-regulating poly (ADP-ribose) polymerase (PARP), Bcl-2 and activating caspase 3, Bax and Bak (Park et al., 2013; Rayalam et al., 2008). Kim et al. (2006) suggested that adipocytes deletion by apoptosis could be a contributor to body fat loss Thus, the use of AKK, AP and VAP might be an appropriate approach to address obesity through adipocyte deletion.

Our results also revealed that KW and VW exerted an antiproliferative effect on HWP during the differentiation period in contrast to the HWP in proliferation stage and more interestingly they decreased cell viability during early stage of differentiation. This action on the differentiation stage was already observed with an omega-3 fatty acid found in fish oil. Indeed, Kim et al. (2006) reported that docosahexaenoic acid (DHA) did not affect cell growth in 3T3-L1 pre-adipocytes. However, after initiation of differentiation, DHA treatment decreased cell viability with an increase in LDH release. They suggested that DHA treatment induced apoptosis in 3T3-L1 during mitotic clonal expansion, occurring during the first few days after initiation of differentiation. In fact, it was reported that two critical events occur during the early stage of differentiation: mitotic clonal expansion and an irreversible commitment to differentiation (Rayalam et al., 2008). We demonstrated that GPL, LKP, IY, KY and VIY have no effect on the viability of HWP neither during proliferation nor differentiation. So they did not target the adipocyte life cycle through controlling adipocyte 
hyperplasia. However, these peptides could act like botanical alkaloids on the commitment to differentiation. Indeed, berberine, which affects the viability of 3T3-L1 during proliferation and differentiation and the viability of HWP cells only during the differentiation, induced a major inhibition of differentiation and finally suppressed adipocyte hypertrophy in both 3T3L1 and HWP cells (Hu, Fahmy, Zjawiony, \& Davies, 2010; Hu \& Davies, 2009).

Therefore, the effect of GPL, IY, VIY, KY, VY and LKP on adipocyte differentiation was evaluated using Oil-Red-O staining, the measure of GPDH activity and the mRNA expression changes of adipocyte differentiation markers.

The Oil-Red-O staining demonstrated that GPL, IY and VIY significantly decreased final lipid content in HWP cells. This inhibition of lipid accumulation was associated with a decrease of GPDH activity, a marker of late adipocyte differentiation only for GPL and IY.

Since GPL and IY seem to affect at least partially adipocyte differentiation, we next investigated the expression of adipocyte specific genes at the same stage of cell cycle to determine their potential mechanism of action.

The adipocyte differentiation process is coordinated by two major classes of transcription factors, namely peroxisome proliferator-activated receptor $\gamma(\operatorname{PPAR} \gamma)$ and CCAAT/enhancer binding proteins (C/EBPs) (Yim, Hosokawa, Mizushina, Yoshida, Saito, \& Miyashita, 2011). These two key regulators of adipogenesis mediate the acquisition of adipocyte phenotype and act synergistically to promote adipogenesis (Rahman et al., 2008).

We measured in the current study the expression of LPL, GLUT4, aP2, AGT, PPAR $\gamma$, and $\mathrm{C} / \mathrm{EBP} \alpha$, genes in response to GPL and IY peptide treatment and observed a significant decrease of their expression levels during HWP cells differentiation between cryptide-treated groups and control-treated groups. Thus, the GPL and IY treatment of maturing HWP might 
358 inhibit at least partially adipogenic activity through the down regulation of PPAR $\gamma$ and $359 \mathrm{C} / \mathrm{EBP} \alpha$.

360 Few previous studies reported some similar effect of peptides derived from other natural 361 sources on adipocyte differentiation. For example, Kim et al. (2007) demonstrated that a 362 tripeptide IQN, purified from a black soybean protein hydrolysate, inhibited adipogenesis of an adipose cell line derived from mouse embryo, through the inhibition of differentiation. More recently, Jung et al. (2011) showed that silk peptides were able to suppress the adipocyte differentiation in C3H10T1/2 and 3T3-L1 cell lines through inhibition of Notch pathway.

The sequences of our most active cryptides, GPL and IY, have been already identified as important in the regulation of various mechanisms. For example, the sequence GPL pertains to the glyproline family (Samonina, Ashmarin, \& Lyapina, 2002), peptide family including proline containing linear peptides, whose most important effects are the suppression of some reactions of blood coagulation and platelet aggregation and the protection of gastric mucosa against various ulcerogenic factors. Moreover, the association of amino-acids from GPL and IY can be found in the sequence of insulin membrane receptor. GPLY forms a recognition signal for insulin receptor endocytosis (Berhanu, Anderson, Paynter \& Wood, 1995). Thus, further work will be undertaken to measure the role of GPL and IY on the insulin pathway.

\section{Conclusion}

We showed in this work that some marine peptides can act on adipose mass by targeting various stages in the life cycle of human white adipocytes. Their ability to affect adipogenesis is not correlated with their ACE-inhibitory activity since LKP and VY have no effect on the 
proliferation and the differentiation of adipocyte cells despite their high inhibitory activity of ACE. AP, VAP and AKK may induce inhibition of growth of preadipocytes during proliferation stage while KW and VW could decrease the number of preadipocytes engaged into the differentiation process. Treatment with GPL or IY inhibited adipogenesis through down-regulating adipocyte specific transcription factors. Lower concentrations of peptides will be checked and the molecular way of action of GPL and IY peptides will be better characterized. We also wish to investigate the GPLY tetrapeptide effect on human white adipocyte cycle, in order to evaluate potent similarities and make a link between insulin pathway and GPL and IY cryptides. These encouraging findings demonstrate for the first time that some cryptides, easily obtained from marine food products, can target the human white adipocyte life cycle. Thus, we believe that these marine cryptides have potential to become associated preventing/treating obesity agents.

\section{Acknowledgements}

The authors thank the Molecular Core Facility of the LIENSs laboratory from the University of La Rochelle. 


\section{References}

401

402

403

404

405

406

407

408

Ben Henda, Y., Labidi, A., Arnaudin, I., Bridiau, N., Delatouche, R., Maugard, T., Piot, J.M., Sannier, F., Thiéry, V., \& Bordenave-Juchereau, S. (2013). Measuring Angiotensin-I converting enzyme inhibitory activity by micro plate assays: comparison using marine cryptides and tentative threshold determinations with captopril and losartan. Journal of Agricultural and Food Chemistry, 61, 10685-10690.

Berhanu, P., Anderson, C., Paynter, D. R., \& Wood, W. M. (1995). The amino acid sequence GPLY is not necessary for normal endocytosis of the human insulin receptor B isoform. Biochemical and Biophysical Research Communications, 209, 730-738.

Bougatef, A., Ravallec, R., Nedjar-Arroume, N., Barkia, A., Guillochon, D., \& Nasri, M. (2010). Evidence of in vivo satietogen effect and control of food intake of smooth hound (Mustelus mustelus) muscle protein hydrolysate in rats. Journal of Functional Foods, 2, 1016.

Bradford, M. (1976). A rapid and sensitive method for the quantitation of microgram quantities of protein utilizing the principles of protein dye binding. Analytical Biochemistry, $72,248-254$.

Catalioto, R. M., Maggi, C. A., \& Giuliani, S. (2009). Chemically distinct HDAC inhibitors prevent adipose conversion of subcutaneous human white preadipocytes at an early stage of the differentiation program. Experimental Cell Research, 315, 3267-3280.

Crandall, D. L., Armellino, D. C., Busler, D. E., McHendry-Rinde, B., \& Kral, J. G. (1999). Ang II receptors in human preadipocytes: role in cell cycle regulation. Endocrinology, 140, $154-158$. 
Engeli, S., Negrel, R., \& Sharma, A.M. (2000). Physiology and pathophysiology of the adipose tissue renin-angiotensin system. Hypertension, 35, 1270-1277.

Furuyashiki, T., Nagayasu, H., Aoki, Y., Bessho, H., Hashimoto, T., Kanazawa, K., \& Ashida, H. (2004). Tea catechin suppresses adipocyte differentiation accompanied by downregulation of PPAR $\gamma 2$ and $\mathrm{C} / \mathrm{EBP} \alpha$ in $3 \mathrm{~T} 3-\mathrm{L} 1$ cells. Bioscience, Biotechnology, and Biochemistry, 68, 2353-2359.

Hammé, V., Sannier, F., Piot, J. M., \& Bordenave-Juchereau, S. (2010). Effects of lactokinins from fermented acid goat whey on lipid content and adipogenesis of immortalised human adipocytes. International Dairy Journal, 20, 642-645.

Hu, Y., \& Davies, G. E. (2009). Berberine increases expression of GATA-2 and GATA-3 during inhibition of adipocyte differentiation. Phytomedicine Int. J. Phytother. Phytopharm, 16, 864-873.

Hu, Y., Fahmy, H., Zjawiony, J. K., \& Davies, G. E. (2010). Inhibitory effect and transcriptional impact of berberine and evodiamine on human white preadipocyte differentiation. Fitoterapia, 81, 259-268.

Jones, B.H., Standridge, M. K., \& Moustaid, N. (1997). Angiotensin II increases lipogenesis in 3T3-L1 and human adipose cells. Endocrinology, 138, 1512-9.

Jung, S. R., Song, N. J., Hwang, H. S., An, J. J., Cho, Y. J., Kweon, H. Y., Kang, S. W., Lee, K. G., Yoon, K., Kim, B. J., Nho, C. W., Choi, S. Y., \& Park, K. W. (2011). Silk peptides inhibit adipocyte differentiation through modulation of the Notch pathway in C3H10T1/2 cells. Nutrition Research, 31, 723-30. 
443

Kim, H. J., Bae, I. Y., Ahn, C. W., Lee, S., \& Lee, H. G. (2007). Purification and identification of adipogenesis inhibitory peptide from black soybean protein hydrolysate. Peptides, 28, 2098-103.

Kim, H. K., Nelson-Dooley, C., Della-Fera, M. A., Yang, J. Y., Zhang, W. Z., Hartzel, D. L., Hamrick, M. W., \& Baile, C. A. (2006). Genistein decreases food intake, body weight, and fat pad weight and causes adipose tissue apoptosis in ovariectomized female mice. Journal of Nutrition 136, 409-14.

Liaset, B., Madsen, L., Hao, Q., Criales, G., Mellgren, G., Marschall H. U., Hallenborg, P., Espe, M., Frøyland, L., \& Kristiansen, K. (2009). Fish protein hydrolysate elevates plasma bile acids and reduces visceral adipose tissue mass in rats. Biochimica et Biophysica Acta, 1791, 254-62.

Massiera, F., Bloch-Faure, M., Ceiler, D., Murakami, K., Fukamizu, A., Gasc, J. M., Quignard-Boulange, A., Negrel, R., Ailhaud, G., Seydoux, J., Meneton, P., \& Teboul, M. (2001). Adipose angiotensinogen is involved in adipose tissue growth and blood pressure regulation. FASEB Journal, 15, 2727-2729.

Ono, S., Hosokawa, M., Miyashita, K., \& Takahashi, K. (2003). Isolation of peptides with angiotensin I-converting enzyme inhibitory effect derived from hydrolysate of upstream chum salmon muscle. Journal of Food Science, 68, 1611-1614.

Park, M. H., Jeon, Y. J., Kim, H. J., \& Han, J. S. (2013). Effect of diphlorethohydroxycarmalol isolated from Ishige okamurae on apoptosis in 3T3-L1 preadipocytes. Phytotherapy Research, 27, 931-936. 
Rahman, A., Kumar, S. G., Kim, S. W., Hwang, H. J., Baek, Y. M., Lee, S. H., Hwang, H. 465 S., Shon, Y. H., Nam, K. S., \& Yun, J. W. (2008). Proteomic analysis for inhibitory effect of 466 chitosan oligosaccharides on 3T3-L1 adipocyte differentiation. Proteomics, 8, 569-81.

Rayalam, S., Della-Fera, M. A., \& Baile, C. A. (2008). Phytochemicals and regulation of the adipocyte life cycle. Journal of Nutritional Biochemistry, 19, 717-26.

Samonina, G., Ashmarin, I., \& Lyapina, L. (2002). Glyproline peptide family: review on bioactivity and possible origins. Pathophysiology, 8, 229-234.

Stothard, K. J., Tennant, P. W., Bell, R., \& Rankin, J. (2009). Maternal overweight and obesity and the risk of congenital anomalies: a systematic review and meta-analysis. Journal of the American Medical Association, 301, 636-50.

Wang, Y. W., \& Jones, P. J. H. (2004). Conjugated linoleic acid and obesity control: efficacy and mechanisms. International journal of obesity and related metabolic disorders, 28, 941955.

Yim, M. J., Hosokawa, M., Mizushina, Y., Yoshida, H., Saito, Y., \& Miyashita, K. (2011). Suppressive effects of Amarouciaxanthin A on 3T3-L1 adipocyte differentiation through down-regulation of PPAR $\gamma$ and $\mathrm{C} / \mathrm{EBP} \alpha$ mRNA expression. Journal of Agricultural and Food Chemistry, 59, 1646-52. 


\section{Oligonucleotide}

Human PPAR $\gamma-\mathrm{R}$

Human PPAR $\gamma-\mathrm{F}$

Human C/EBP $\alpha-\mathrm{R}$

Human $\mathrm{C} / \mathrm{EBP} \alpha-\mathrm{F}$

Human LPL-R

Human LPL-F

Human aP2-R

Human aP2-F

Human GLUT4-R

Human GLUT4-F

Human AGT-R

Human AGT-F

Human $\beta$-actin-R

Human $\beta$-actin-F
Sequences (5', to 3')

GGCGGTCTCCACTGAGAATA

GAGCCCAAGTTTGAGTTTGC

TTTAGCAGAGACGCGCACATTCAC

ATTGCCTAGGAACACGAAGCACGA

CTGGCATTGCAGGAAGTCTG

GCATCATCAGGAGAAAGACGA

TCTCTTTATGGTGGTTGATTTT

CAGTGTGAATGGGGATGTG

TTTCACCTCCTGCTCTAA

CGTCTTCCTTCTATTTGC

AGGCATAGTGAGGCTGGAT

CCTGGCTTTCAACACCTAC

GCCTCGTCGCCCACATAG

GCCGTCTTCCCCTCCATC 

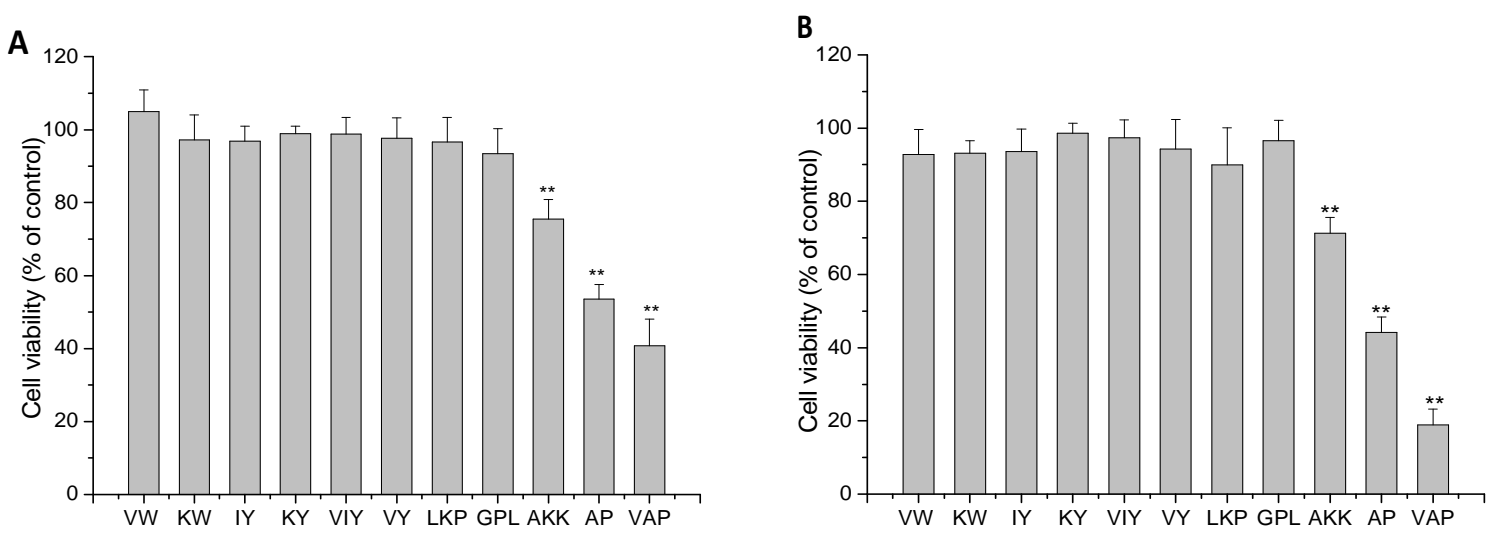

499

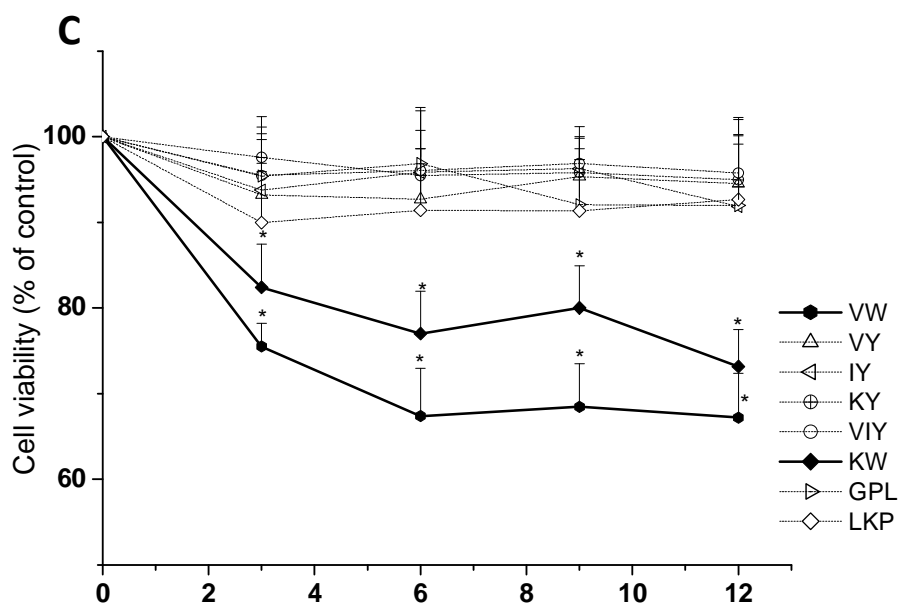

500

501 Figure 1

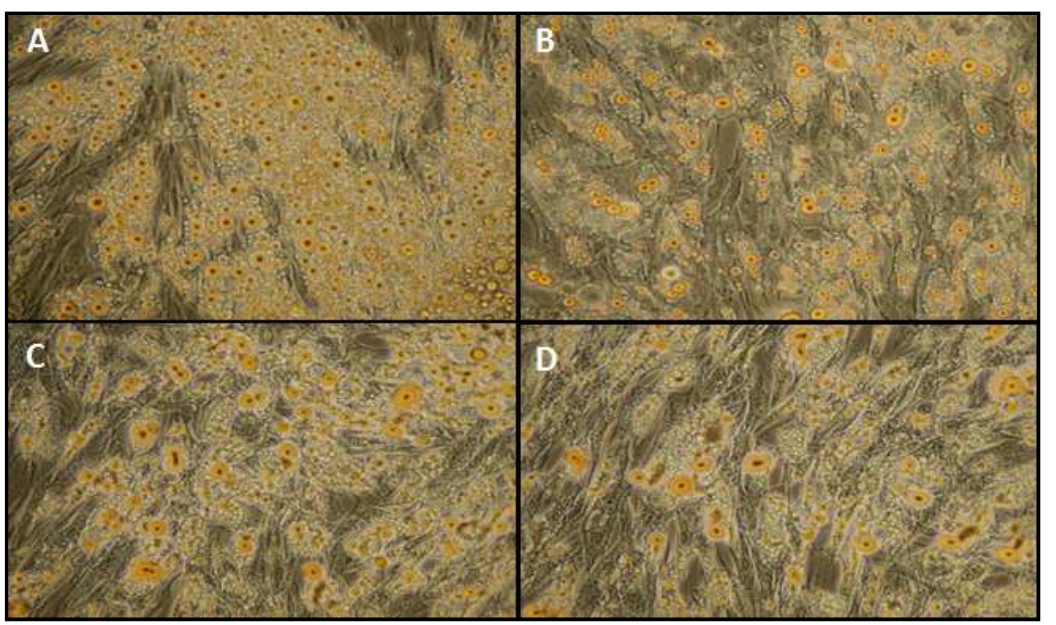

Figure 2 


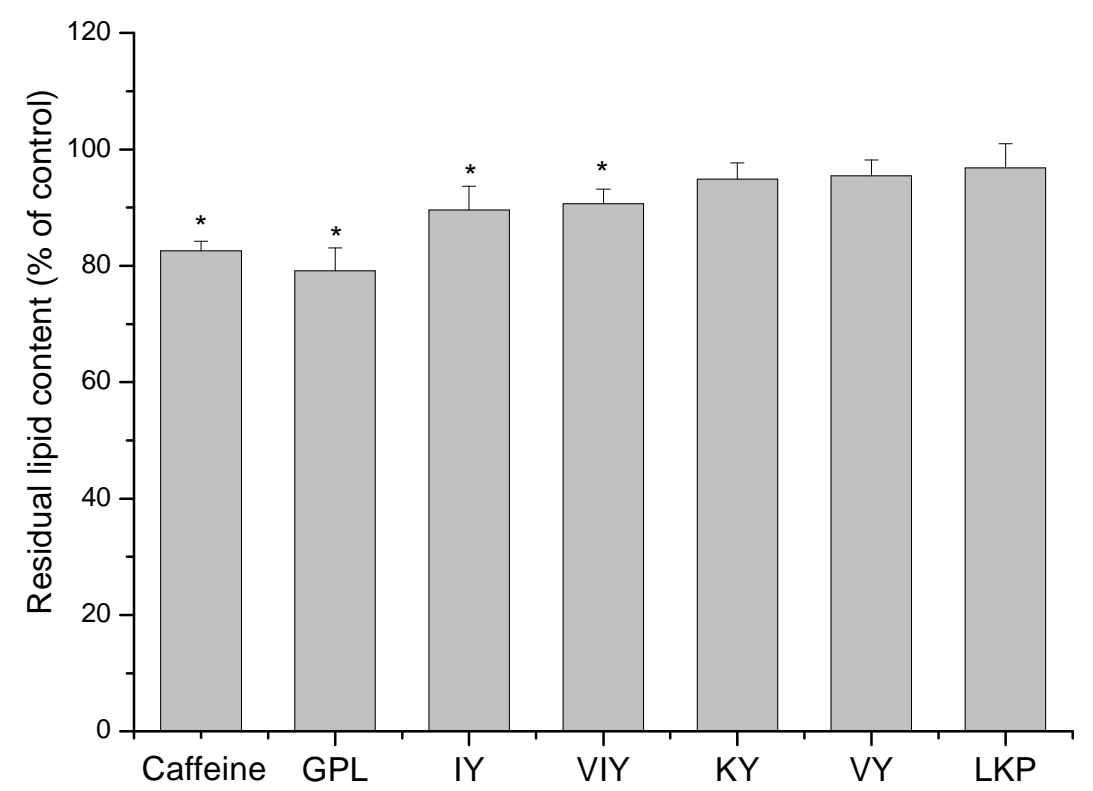

505

$506 \quad$ Figure 3

507

508

509

510

511

512 


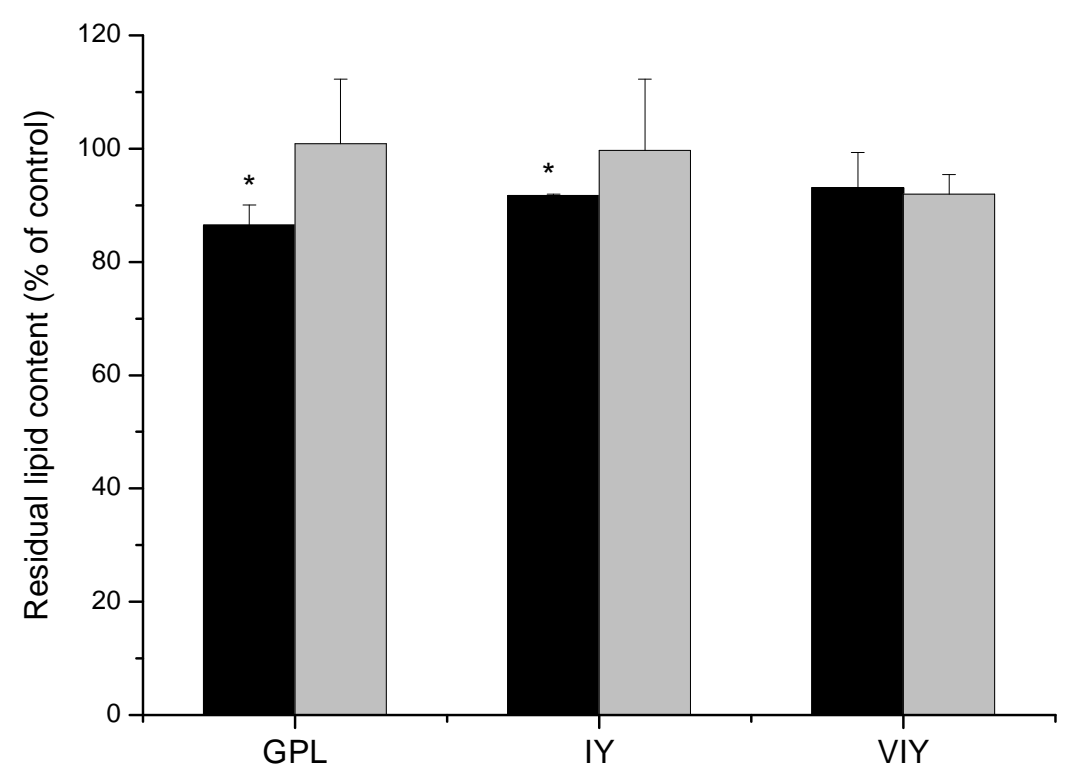

513

$514 \quad$ Figure 4

515

516

517

518

519

520

521

522

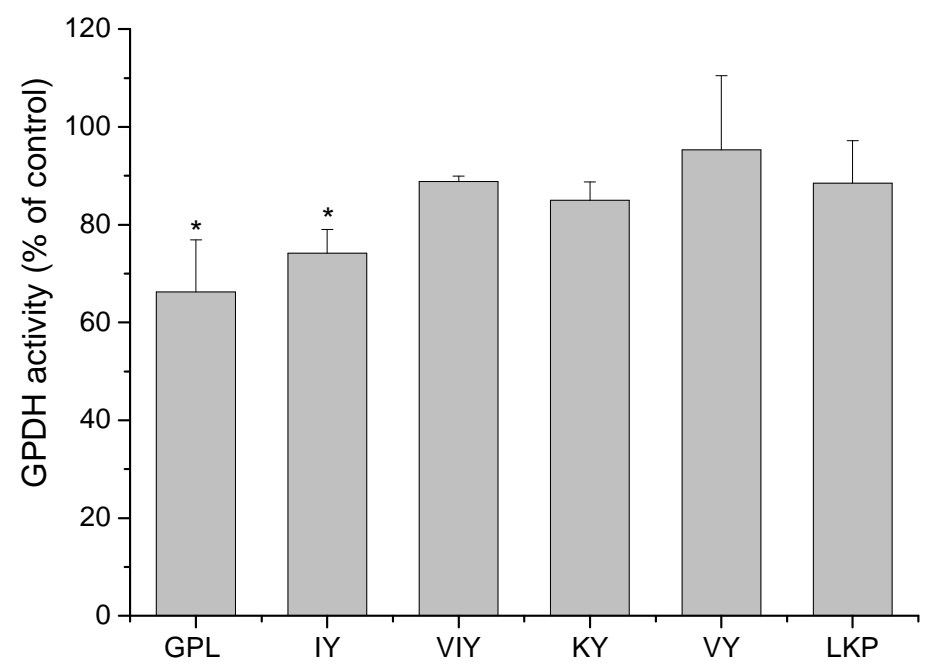

523

$524 \quad$ Figure 5

525 

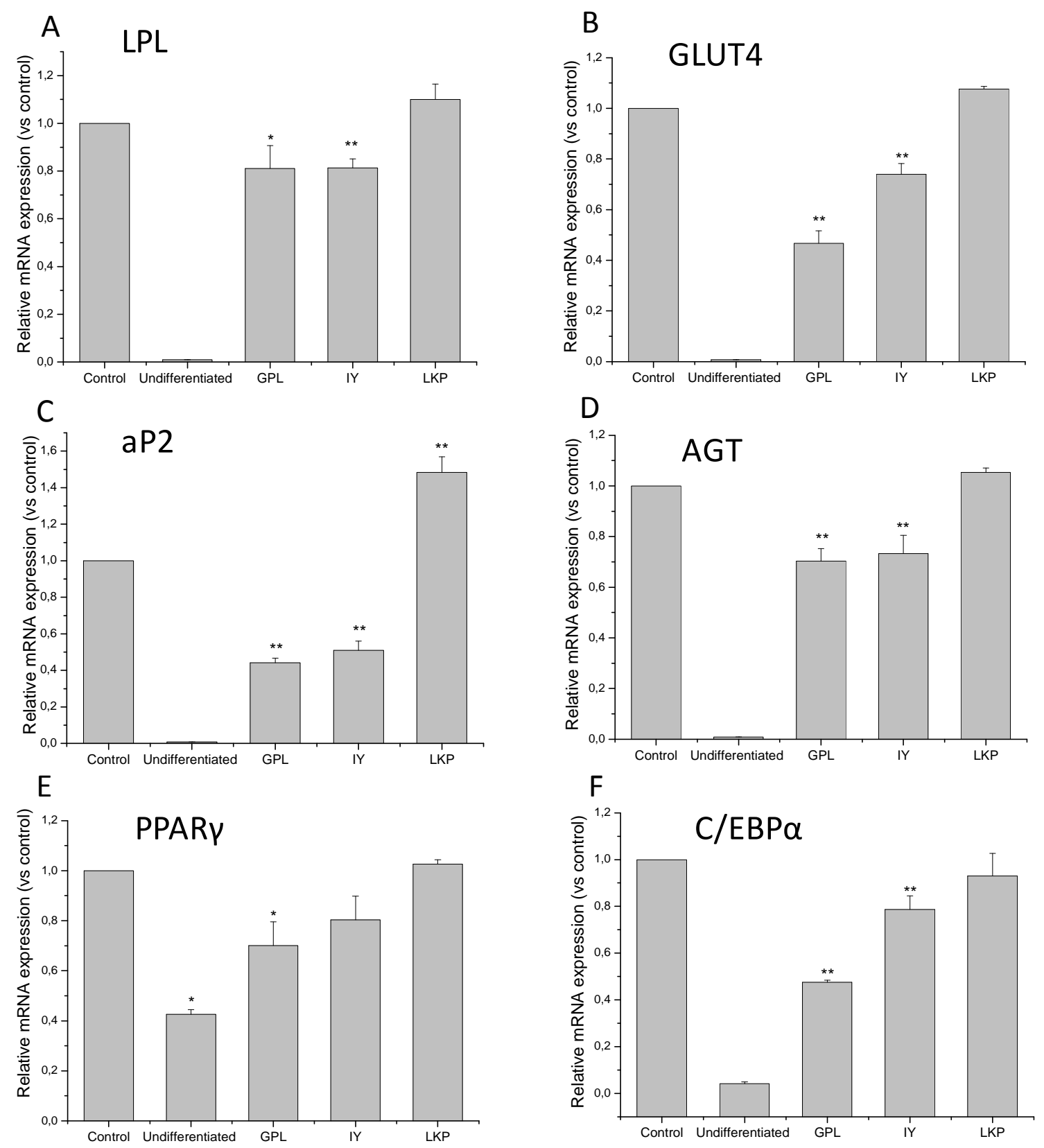

$527 \quad$ Figure 6 
Figure 1:

Effect of cryptides on cell viability of HWP during proliferation after $24 \mathrm{~h}$ (A) and $72 \mathrm{~h}$ (B) of treatment and after 3, 6, 9 and 12 days of differentiation (C). Cell viability was expressed as

533 percentage of non-treated cells (control). (A) and (B) Pre-confluent cells were treated with $534100 \mu \mathrm{M}$ of peptides (VW, KW, IY, KY, VIY, VY, VIY, LKP, GPL, AKK, AP, VAP) at $24 \mathrm{~h}$

535 after cell plating. (C) Differentiation of HWP at confluence was induced and cells were 536 treated with $100 \mu \mathrm{M}$ of peptides (VW, VY, IY, KY, VIY, KW, GPL, LKP) in appropriate medium. Values are means \pm SEM, $n=24$ replicates. $*$ denotes significant difference compared 538 with non-treated group $(p<0.05)$ and. $* *(p<0.01)$.

\section{Figure 2:}

542 Effect of cryptides on lipid content of mature adipocytes. Cells were treated during 543 differentiation period (from day 0 to day 16) control (A), $100 \mu \mathrm{M}$ of GPL (B), IY(C) and 100 $544 \mu \mathrm{M}$ caffeine (D).

545 Figure 3:

546 Effect of cryptides on residual lipid content of mature adipocytes. Values were presented as 547 percentage of non-treated cells (control) optical density. Cells were treated throughout the 548 differentiation period (from day 0 to day 16) with $100 \mu \mathrm{M}$ of caffeine, GPL, IY, VIY, KY, 549 VY and LKP. Values are means \pm SEM, $n=12$ replicates. *denotes significant difference 550 compared with non-treated group $(p<0.05)$. 
552 Figure 4:

553 Effect of cryptides on residual lipid content of mature adipocytes treated at different stage of 554 the differentiation process. Values were expressed as percentage of non-treated cells (control). 555 Cells were treated during differentiation process from day 0 to day 4 ( $\mathbf{a}$ ) or form day 4 to day $55616(\square)$ with $100 \mu \mathrm{M}$ of GPL, IY and VIY. Values are means \pm SEM, $n=12$ replicates.

$557 *$ denotes significant difference compared with non-treated group $(p<0.05)$.

558 Figure 5:

559 Effect of cryptides on Glycerol-3-phosphate dehydrogenase (GPDH) specific activity of 560 HWP. GPDH activity was presented as percentage of the activity of non-treated cells 561 (control). Cells were treated during differentiation form day 0 to day 8 in the presence of 100 $562 \mu \mathrm{M}$ of GPL, IY, VIY, KY, VY and LKP. Values are means \pm SEM, $n=3$ replicates. *denotes 563 significant difference compared with non-treated group $(p<0.05)$.

564 Figure 6:

565 Effect of GPL, IY and LKP on mRNA expression of LPL (A), GLUT 4 (B), aP2 (C), AGT 566 (D), PPAR $\gamma(\mathrm{E})$ and $\mathrm{C} / \mathrm{EBP} \alpha(\mathrm{F})$ during HWP differentiation. Cells were treated during 567 differentiation from day 0 to day 8 in the presence of $100 \mu \mathrm{M}$ of GPL, IY and LKP. The 568 mRNA expression levels were measured by real time PCR and expressed as a ratio to non569 treated cells (control) levels $(=1.0)$ after normalization using the $\beta$-actin mRNA expression 570 level. Values given are the means \pm S.D. $(n=3)$, ** and $*$ denotes significant differences 571 compared with non-treated cell $(\mathrm{p}<0.01)$ and $(\mathrm{p}<0.05)$. 